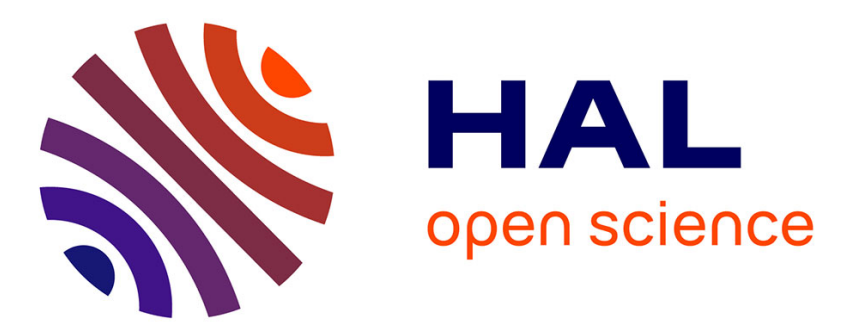

\title{
Generalization of force-field adaptation in proprioceptively-deafferented subjects
}

Hannah Z. Lefumat, R. Chris Miall, Jonathan D. Cole, Lionel Bringoux, Christophe Bourdin, Jean-Louis Vercher, Fabrice R. Sarlegna

\section{To cite this version:}

Hannah Z. Lefumat, R. Chris Miall, Jonathan D. Cole, Lionel Bringoux, Christophe Bourdin, et al.. Generalization of force-field adaptation in proprioceptively-deafferented subjects. Neuroscience Letters, 2016, 616, pp.160-165. 10.1016/j.neulet.2016.01.040 hal-01436017

\section{HAL Id: hal-01436017 https://hal.science/hal-01436017}

Submitted on 2 May 2018

HAL is a multi-disciplinary open access archive for the deposit and dissemination of scientific research documents, whether they are published or not. The documents may come from teaching and research institutions in France or abroad, or from public or private research centers.
L'archive ouverte pluridisciplinaire HAL, est destinée au dépôt et à la diffusion de documents scientifiques de niveau recherche, publiés ou non, émanant des établissements d'enseignement et de recherche français ou étrangers, des laboratoires publics ou privés. 
Research paper

\title{
Generalization of force-field adaptation in proprioceptively-deafferented subjects
}

\author{
Hannah Z. Lefumat ${ }^{\mathrm{a}}$, R. Chris Miall ${ }^{\mathrm{b}}$, Jonathan D. Cole ${ }^{\mathrm{c}, \mathrm{d}}$, Lionel Bringoux ${ }^{\mathrm{a}}$, \\ Christophe Bourdin ${ }^{a}$, Jean-Louis Vercher ${ }^{a}$, Fabrice R. Sarlegna ${ }^{\mathrm{a}, *}$ \\ a Aix-Marseille Université, CNRS, ISM UMR 7287, 13009 Marseille, France \\ b School of Psychology, University of Birmingham, Birmingham B15 2TT, UK

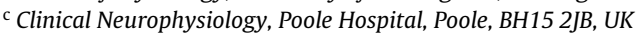 \\ d School of Psychology, Bournemouth University, Poole, BH12 5BB, UK
}

\section{H I G H L I G H T S}

- Motor learning generalizes across limbs and movement directions.

- Proprioception is supposedly critical for the learning and control of limb dynamics.

- The role of proprioception can be assessed by testing subjects deprived of proprioceptive afferences.

- Intermanual transfer can be observed in two deafferented patients.

- The loss of proprioception does not preclude generalization of motor learning.

\section{A R T I C L E I N F O}

\section{Article history:}

Received 6 November 2015

Received in revised form 11 January 2016

Accepted 23 January 2016

Available online 28 January 2016

\section{Keywords:}

Vision

Proprioception

Deafferentation

Coriolis force adaptation

Intermanual transfer

Human motor learning

\begin{abstract}
A B S T R A C T
Humans have the remarkable ability to adapt their motor behaviour to changes in body properties and/or environmental conditions, based on sensory feedback such as vision and proprioception. The role of proprioception has been highlighted for the adaptation to new upper-limb dynamics, which is known to generalize to the opposite, non-adapted limb in healthy individuals. Such interlimb transfer seems to depend on sensory feedback, and the present study assessed whether the chronic loss of proprioception precludes interlimb transfer of dynamic adaptation by testing two well-characterized proprioceptively-deafferented subjects. These had to reach toward visual targets with vision of the limb. For both deafferented subjects, we observed adaptation of the dominant arm to Coriolis forces and aftereffects on non-dominant arm movements in different movement directions, thus indicating interlimb transfer. Overall, our findings show that motor learning can generalize across limbs and movement directions despite the loss of proprioceptive afferents.
\end{abstract}

(c) 2016 Elsevier Ireland Ltd. All rights reserved.

\section{Introduction}

The properties of the body and the environment change from time to time but sensory feedback such as vision and proprioception help minimizing motor errors via iterative, trial-by-trial corrective mechanisms. A common example is that humans, who wear prisms for instance, can adapt to the novel relationship between a visual input (e.g. an object on a table) and the motor output [1-5]. When specifically considering voluntary arm movements, it is well known

* Corresponding author at: Institute of Movement Sciences, CNRS \& Aix Marseille University (UMR 7287), 163 av. de Luminy-CP 910, 13009 Marseille, France.

E-mail address: fabrice.sarlegna@univ-amu.fr (F.R. Sarlegna). that humans can restore accurate reaching despite changes in limb dynamics [6-8].

The adaptive control of limb dynamics has been suggested to critically depend on proprioception [4,9]. Studies of subjects deprived of proprioceptive afferents showed that proprioception is critical for the coordination of daily actions such as walking or arm reaching [9-11]. Ghez and Sainburg [9] suggested that proprioceptive information is required to update the internal representation of limb dynamic properties. Moreover, studies on healthy subjects deprived of vision showed that proprioception is sufficient to adapt to new limb dynamics [6,12] and that adaptation to a novel force field is similar with or without vision $[7,8,13]$. Nevertheless, it has recently been shown that proprioceptively-deafferented subjects could adapt, with visual feedback, to new dynamics of the 
dominant arm $[14,15]$. Both studies thus provided experimental evidence that dynamic adaptation is possible without proprioception as its permanent loss can be compensated by vision. However, it remains unknown whether such adaptation, without proprioception, can generalize to movements that have not been experienced previously. For instance, adaptation of arm movements in a single direction can generalize to movements of the same arm in neighboring directions $[3,13]$. Adaptation of one arm can also benefit movements of the opposite arm [13,16-18] although such interlimb transfer is generally limited [19-21] and sometimes is not observed [22]. In fact, it remains unclear which factors influence how we transfer what we have learned from one limb to the other.

Cohen [2] proposed that interlimb transfer of sensorimotor adaptation depends on sensory feedback, since transfer of prism adaptation was only observed when vision of the moving limb was precluded, i.e. when peripheral feedback control relies only on proprioception. Here we directly tested the hypothesis that proprioception is important for the interlimb transfer of sensorimotor adaptation [23]: specifically, we examined the motor behaviour of two well-characterized deafferented individuals $[5,10,14]$ to assess interlimb transfer of adaptation to new Coriolis forces in the absence of limb proprioception. As in similar studies [6,13], we hypothesized that interlimb transfer would result in a deviation of the first reaching movement of the non-dominant arm after adaptation of the dominant arm.

\section{Methods}

\subsection{Subjects}

Two subjects deprived of body proprioception (GL and IW) participated in the experiment. GL and IW suffered an acute sensory neuronopathy (when they were 31 and 19 years old, respectively) which resulted in the specific loss of large-diameter, $A \beta$ myelinated afferent fibers: both individuals have thus lost kinesthesia, tendon reflexes, touch, vibration, pressure, as well as position and movement sense of all body parts, from nose down for GL (trigeminal division 3) and from neck down for IW (C3 root level). Both individuals perceive pain and temperature, suggesting that small fibers are intact, as confirmed by a biopsy for GL [24]. Examination by specialists of the visual system revealed no deficit in either patient. Examination of GL by specialists of the vestibular system revealed no deficit, in line with previous examination [25]. No vestibular deficits have been found for IW [26].

$\mathrm{GL}$, a right-handed woman, was 66 year old at the time of the experiment, and IW, a left-handed man, was 61. The Edinburgh Inventory (10-item version, [27]) revealed a Laterality Quotient of $+77 \%$ for GL and $-100 \%$ for IW. Both subjects were naive to the purpose of the experiment. They gave their informed consent prior to the study, which was approved by the institutional review board of the Institute of Movement Sciences and performed in accordance with the ethical standards of the Declaration of Helsinki.

\subsection{Experimental set-up}

Subjects sat at the center of a motorized platform (Fig. 1A) which could rotate and thus generate a Coriolis, velocity-dependent force field on the moving limb. A bucket seat and a headrest were used to restrain trunk and head motion. On a horizontal board, at waist level, a visual landmark indicated the starting hand position and visual targets were displayed using low-intensity red light-emitting diodes ( $3 \mathrm{~mm}$ in diameter). Three targets were positioned on a $37 \mathrm{~cm}$ radius circular array at $0^{\circ}$ (straight-ahead), $20^{\circ}$ (to the right) and $-20^{\circ}$. Full vision of the upper limb and the workspace was available throughout the experiment. The positions of infrared active markers taped on the right and left index fingertips were sampled at $350 \mathrm{~Hz}$ using an optical motion tracking system (Codamotion cx1 and MiniHub, Charnwood Dynamics Ltd, Leicestershire, UK).

\subsection{Procedure}

Methods were similar in a previous study [13]. Subjects had to position their hand at the starting location (Fig. 1A) and to perform unconstrained, forward reaching movements as fast and accurately as possible toward the visual target which was illuminated for $0.3 \mathrm{~s}$. No explicit instructions were given with respect to hand movement except 'reach in one movement' and 'avoid correcting after the finger contacted the board'. A $100-\mathrm{ms}$ tone informed subjects, $1.6 \mathrm{~s}$ after trial onset, to go back slowly to the starting location. A 600$\mathrm{ms}$ tone signalled trial end $7.4 \mathrm{~s}$ after trial onset. Peak velocity of the reach was $\sim 10$ times greater than that of the backward movement toward the start position. Subjects were familiarized with the task before starting the experimental session, which consisted of 3 phases (Fig. 1B):

- PRE-rotation test

30 reaching movements with the dominant arm (DA) then with the non-dominant arm (NDA) toward one of three targets (10 trials per target for each hand, in a pseudorandom order which was similar for both subjects) while the platform remained stationary, providing baseline performance. After the PRE-rotation test, the rotating platform was accelerated in $80 \mathrm{~s}$ up to a constant velocity of $120^{\circ} / \mathrm{s}(20 \mathrm{rpm})$.

- PER-rotation phase

100 movements with the DA to the central target. For the right-handed subject GL, the platform rotated counterclockwise at $120^{\circ} / \mathrm{s}$, generating tangential clockwise Coriolis forces on the moving limb. For the left-handed subject IW, a clockwise rotation was used to match the biomechanical consequences of the perturbation on the dominant arm [13]. After the PER-rotation phase, the rotating platform decelerated to a stop in 80 s.

- POST-rotation test

Similar to the PRE-rotation test except that the NDA was tested before the DA. The first presented target was the central one (then left, right...).

A 60s delay between the end of the platform's acceleration and deceleration phases and the ensuing reach allowed the vestibular semi-circular canals to return to their resting discharge frequency [28]. Subjects were instructed not to move their opposite arm and their head during the experiment.

\subsection{Data analysis}

Data were analysed with Matlab (Mathworks, Natick, MA, USA). Position data from the markers on the right and left index fingertips were low-pass filtered with a dual-pass, no-lag Butterworth (cut-off frequency: $8 \mathrm{~Hz}$; order: 2). Movement onset and end were defined as the first time tangential hand velocity reached above and below $3 \mathrm{~cm} / \mathrm{s}$.

Initial direction was computed as the angle between the vector start position-target position and the vector start position-hand position at $150 \mathrm{~ms}$ after movement onset. This early assessment precluded most visuomotor corrections [29]. For all measures, we assigned positive values to rightward deviations and vice-versa.

We mostly used $t$-tests comparisons of a single value to a sample $[14,30]$ with a conservative significance threshold of 0.01 (thus corresponding to a $99 \%$ confidence interval) to minimize type I errors. For instance, to assess adaptation, we compared for each subject the DA initial direction of the first movement in the POST-rotation 

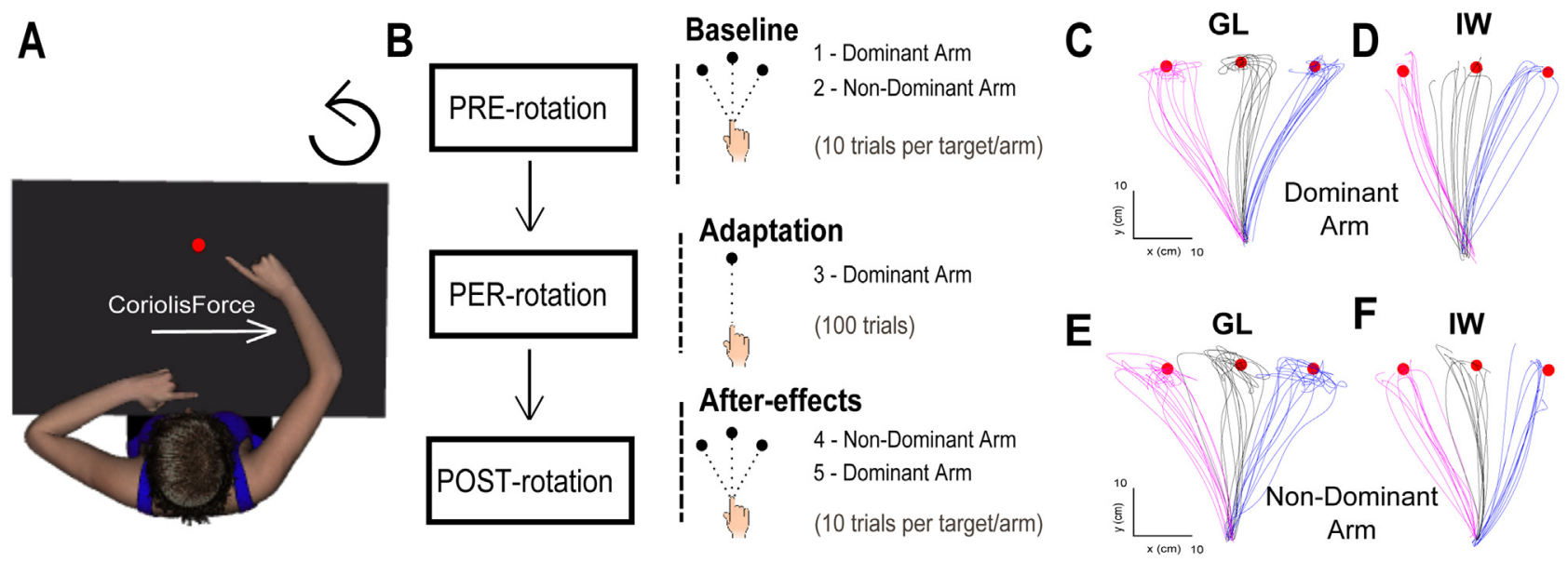

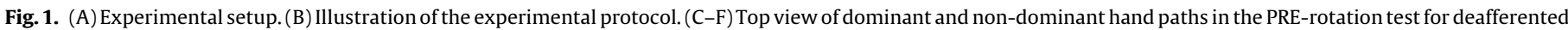
subjects GL and IW.

test to the corresponding 10 trials (DA movements toward the central target) from the PRE-rotation test. To assess interlimb transfer, we compared the NDA initial direction in the first trial of the POSTrotation phase to the corresponding trials in the PRE-rotation test.

The magnitude of the perturbation (of the PER-rotation phase) as well as the after-effects (DA) and the transfer value (NDA) were defined by using the formula: $t_{i}=\left(X_{i}-\mu_{i}\right) / S E_{i}$, where, for each subject $i, X$ was the initial direction of the given trial (i.e. first trial of the PER or POST-rotation phase), $\mu_{i}$ the initial direction averaged across the movements of the corresponding trials in the PRE-rotation test and $S E$ the standard error of the PRE-rotation test.

\section{Results}

\subsection{Adaptation of deafferented subjects' dominant arm (DA) to a novel force field}

DA movements of both subjects were fast in PRE-, PER- and POST-rotation phases. On average across these 3 phases, IW and GL's mean peak velocity ( \pm SD) was $2.8 \pm 0.3$ and $2.3 \pm 0.3 \mathrm{~m} / \mathrm{s}$, respectively. IW and GL's overall movement duration was $447 \pm 64$ and $600 \pm 163 \mathrm{~ms}$ while time-to-peak-velocity was $161 \pm 20$ and $173 \pm 35 \mathrm{~ms}$, respectively. As in previous work [14], we observed during the PRE-rotation test that DA movements with visual feedback but without proprioception were generally accurate in term of endpoint error but were also quite variable, especially when considering movement trajectory (Fig. 1C and D).

The initial direction of the first movement of the PER-rotation phase was substantially shifted by the Coriolis force relative to the PRE-rotation test $\left(\mathrm{GL}:+12.7^{\circ}, t(9)=6.8\right.$; IW: $+12.1^{\circ}, t(9)=5.1$; $p<0.001$ for both; Fig. 2A). For both, such shift was similar to that of the healthy subjects in our previous study [13] (GL: $t(19)=0.5$, $p=0.6$; IW: $t(19)=-1.8, p=0.09$ ). Debriefing at the end of the experiment revealed that IW noticed unusual trajectory errors in the first PER-rotation trials while GL did not consciously perceive that movement trajectory differed from usual.

Analyses of hand path and initial direction during the PER- and POST-rotation trials indicate that both GL and IW adapted to the novel force field (Fig. 2), which also highlights the variability in initial direction across the adaptation phase (mean initial direction across 100 trials: $\mathrm{GL}=-3.6 \pm 6^{\circ} ; \mathrm{IW}=-7.9 \pm 5.6^{\circ}$. GL adapted in 3 trials and IW in 2 trials, as the healthy subjects from our previous experiment [13]. GL's and IW's variability of initial direction was higher at the beginning (10 first trials) than at the end (10 last trials) of the PER-rotation phase (IW: first $S D=6$, last $S D=3.7$; GL: first $\mathrm{SD}=7.3$, last $\mathrm{SD}=4.3$ ). In the first trial of the POST-rotation test with the DA (performed after the POST-test with the NDA), aftereffects were observed in IW (mean shift relative to baseline $=-10.2^{\circ}$, $t(9)=-3.6, p<0.01)$ and GL ( $\left.\operatorname{shift}=-4.7^{\circ}, t(9)=-2.8, p=0.02\right)$. Such after-effects were smaller than that of the healthy subjects in our previous study [13] (GL: $t(19)=6$; IW: $t(19)=5.6 ; p<0.001$ for both).

We tested different target directions in PRE- and POST-rotation tests to assess whether the force-field adaptation of DA movements toward the central target generalized to DA movements performed in other directions $\left(+20^{\circ}\right.$ and $\left.-20^{\circ}\right)$. We observed generalization for IW as the initial direction of the first movement toward the left and right targets was shifted compared to the corresponding trials (left target: mean PRE-rotation test $=-2.3 \pm 3.3^{\circ}$ vs. first POST-rotation trial $=-11.8^{\circ}, t(9)=-9.2, p<0.001$; right target: mean PRE-rotation test $=-11.3 \pm 8.2^{\circ}$ vs. first POST-rotation trial $\left.=-1.3^{\circ}, t(9)=-3.9, p<0.01\right)$. For $G L$, generalization across movement direction was marginally significant for the first DA movement of the POST-rotation test toward the right target (mean PRE-rotation test $=-8.0 \pm 5.2^{\circ}$ vs. first POST-rotation trial $=-12.5^{\circ}$, $t(9)=-2.7, p=0.02$ ) but not for the left target (mean PRE-rotation test $=-3.0 \pm 4.6^{\circ}$ vs. first POST-rotation trial $=-5.0^{\circ} ; t(9)=-1.4$, $p=0.2$ ).

\subsection{Interlimb transfer of dynamic adaptation in deafferented subjects}

For both subjects, NDA movements were fast in PRE- and POSTrotation phases. On average across these 2 phases, IW and GL's peak velocity was $2.7 \pm 0.3$ and $2.2 \pm 0.4 \mathrm{~m} / \mathrm{s}$, movement duration was $460 \pm 60$ and $705 \pm 90 \mathrm{~ms}$ and time-to-peak-velocity was $160 \pm 10$ and $207 \pm 56 \mathrm{~ms}$, respectively. Fig. $1 \mathrm{E}$ and $\mathrm{F}$ shows that baseline NDA movements were fairly accurate but movement trajectory was variable.

When we compared NDA initial direction in the first trial of the POST-rotation test to the NDA initial direction in the 10 PRE-rotation movements toward the central target (Fig. 2D), a substantial difference was found $\left(\mathrm{GL}=-13.3^{\circ}, t(9)=-7.9 ; p<0.001\right.$; $\left.\mathrm{IW}=-8.2^{\circ}, t(9)=7 ; p<0.001\right)$. This indicates that Coriolis-force adaptation transfers from the DA to NDA.

The transfer value of deafferented subjects was greater (GL: $t(19)=6.01$; IW: $t(19)=5.2 ; p<0.001$ for both) than that of the 20 healthy right-handers tested in our previous study [13]. It is worth noting that healthy subjects had similar kinematics (mean peak velocity $=2.5 \pm 0.9 \mathrm{~m} / \mathrm{s}$; mean movement duration $=426 \pm 16 \mathrm{~ms}$; mean time-to-peak-velocity $=152 \pm 26 \mathrm{~ms}$ ) to those of GL and IW 

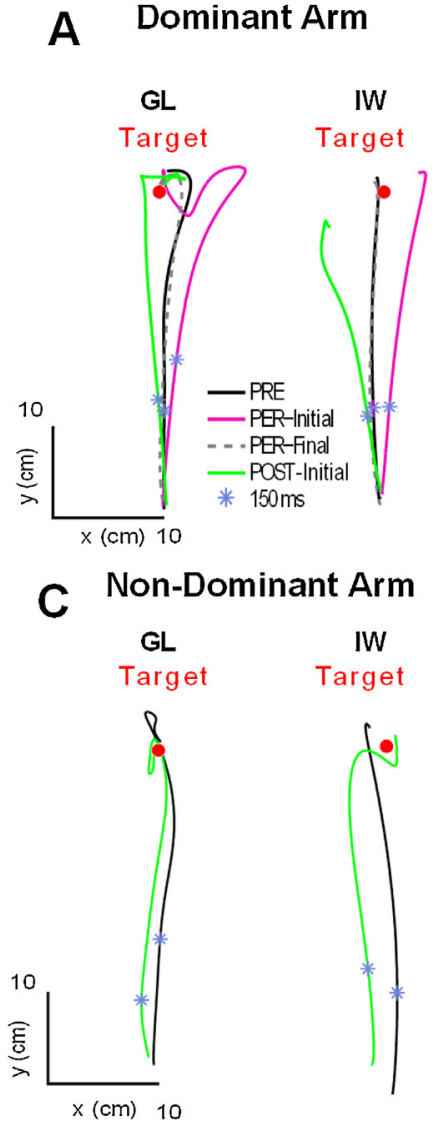

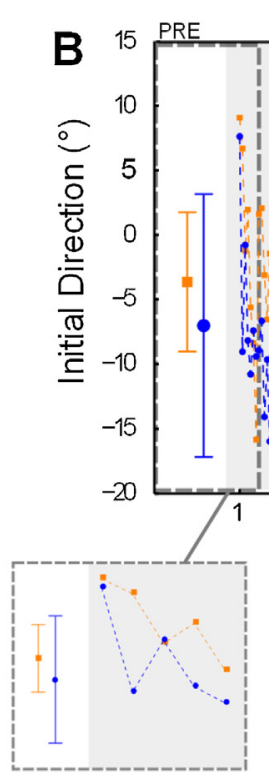

PER-rotation phase POST

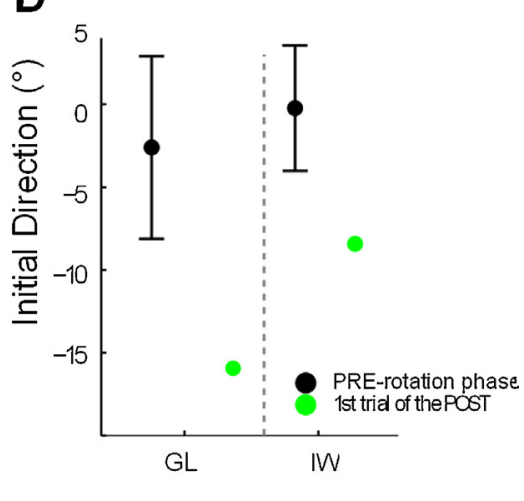

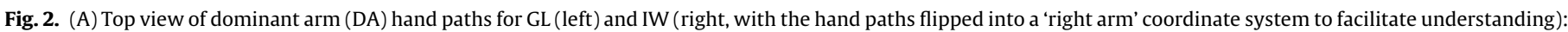

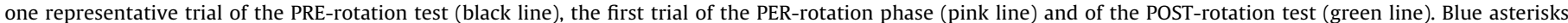

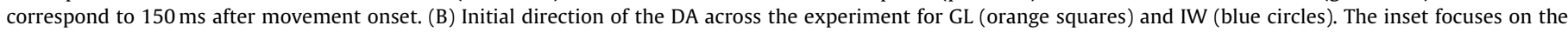

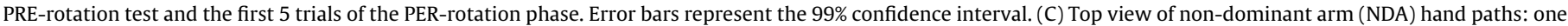

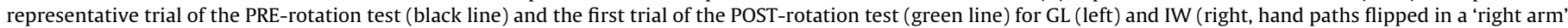

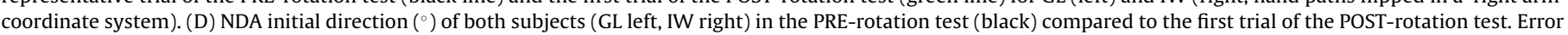
bars represent the $99 \%$ confidence interval. (For interpretation of the references to colour in this figure legend, the reader is referred to the web version of this article.)

in the present study. In Lefumat et al. [13], we found that interlimb transfer varied with individual characteristics such as laterality quotient and movement kinematics. In particular, the transfer value increased with the laterality quotient ( mean $=83.7 \pm 11 \%$ ), the variability of initial direction across the last 10 trials of the adaptation phase (mean $=3.2 \pm 0.9^{\circ}$ ) and the peak velocity of movements across the PER-rotation phase (mean $=2.5 \pm 0.3 \mathrm{~m} / \mathrm{s}$ ). A classification model using these 3 variables was trained using the data from the 20 healthy right-handers [13] and then tested with the dataset from the 2 deafferented subjects. Given that GL and IW were both well lateralized ( +77 and $-100 \%$ respectively) and performed quite rapid DA movements across the PER-rotation phase $(2.5 \mathrm{~m} / \mathrm{s}$ for both subjects), with substantial variability in initial direction across the last 10 learning trials (GL: $5.1^{\circ}$; IW: $3.5^{\circ}$ ), the model (correctly) predicted that interlimb transfer of Coriolis force adaptation would be observed for GL and IW with a 99\% probability for each.

Considering more quantitative aspects, we used the same 3 variables of the same healthy subjects $(n=20)$ to build a regression model with the transfer value as the dependent variable. Using this model with deafferented subjects' data, we found that the predicted transfer value did not significantly differ from the observed value (GL: $p=0.20$; IW: $p=0.15$ ). Second, as some of these variables, in particular variability, were greater for the deafferented subjects compared to the healthy subjects, a greater transfer value was predicted for the deafferented subjects compared to the healthy subjects.
The NDA movements in PRE- and POST-rotation tests allowed us to determine whether Coriolis force adaptation of DA movements toward the central target generalized to NDA movements in other directions. Our findings revealed generalization across limbs and across movement directions for IW as the first NDA movement toward the left target (initial direction $=-13^{\circ}$ ) differed from the PRE-rotation movements toward the left target (mean $=-4.0 \pm 8.0^{\circ} ; t(9)=3.5, p<0.01$ ). For IW, generalization was marginally significant for the right target (mean PRE-rotation test $=4.4 \pm 6.0^{\circ}$ vs. first POST-rotation trial $=0.2^{\circ}$; $t(9)=-2.2, p=0.06$ ). For GL, DA adaptation of movements toward the central target generalized to the NDA movements toward the right target (mean PRE-rotation test $=-5.0 \pm 7.6^{\circ}$ vs. first POSTrotation trial $=-15.0^{\circ} ; t(9)=-4.1, p<0.01$ ) and the left target (mean PRE-rotation test $=4.8 \pm 5.7^{\circ}$ vs. first POST-rotation trial $=-0.1^{\circ}$; $\mathrm{t}(9)=-2.7, p<0.01)$.

\section{Discussion}

Cohen [2] proposed that interlimb transfer of sensorimotor adaptation depends on sensory feedback and the present study was designed to directly test the hypothesis that proprioceptive feedback is critical for the interlimb transfer of force-field adaptation. We asked two deafferented subjects to perform reaching movements with both arms, with continuous visual feedback. For both subjects, we observed adaptation of the dominant arm to Coriolis forces, after-effects on the dominant arm movements but also 
after-effects on the non-dominant arm movements, thus indicating interlimb transfer. Given that adaptation of dominant arm movements influenced subsequent non-dominant arm movements in different directions, this study shows that motor learning can generalize across limbs and movement directions despite the loss of proprioceptive afferences.

Our findings of two deafferented subjects adapting to a novel force field replicate and extend those obtained in previous studies with GL [14] and IW [15]. The finding of adaptation, interlimb transfer and generalization across movement directions in both subjects highlights the sufficiency of vision to provide information for motor control and learning [9]. The importance of vision in motor learning was also emphasized in other studies which showed that viewing another person adapting to a novel force field can result in improvements in reaching performance in the force field and even to some form of interlimb transfer [31]. In the present study, comparing the motor commands to their visual consequences was sufficient to result in sensorimotor adaptation, as in Bernier et al. [1]. and in generalization across limbs and movement directions.

In our recent study on healthy subjects [13], force-field adaptation was similar with or without visual feedback, in line with previous studies [7,8,12]. Moreover, interlimb transfer was similar with or without visual feedback: this could be seen as evidence that vision is not necessary for force-field adaptation and interlimb transfer [6]. However, the present findings would suggest that proprioception too is not necessary for force-field adaptation and generalization. Altogether, these findings suggest that neither proprioception nor vision is critical for sensorimotor adaptation and interlimb transfer, as long as one modality is available [2,7,11,32].

In the present study and our previous study [13], we observed a shift in the initial direction of the non-dominant arm after dominant arm adaptation. This shift was in the opposite direction of the perturbation in Cartesian space, similar to that of the dominant arm: this is consistent with the idea of a central representation of limb dynamics in extrinsic coordinates $[6,16,17]$. In our previous study [13], three main factors determined interlimb transfer in healthy subjects: laterality quotient [27] as well as variability of initial direction and peak velocity during the adaptation phase. Based on these data, we could make qualitative and quantitative predictions of interlimb transfer: these were consistent with our observations on two older subjects with the rare condition of selective proprioceptive deafferentation. This seems to reinforce the general validity, and the predictive ability, of our findings on interlimb transfer. Both deafferented subjects may have benefited from their high motor variability in the adaptation phase, which could facilitate action exploration and thus finding the most efficient movement strategy [33]. Whether this variability reflects a cognitive strategy or results from difficulties to control limb dynamics after the proprioceptive loss remains unclear and will require additional experiments.

Laterality quotient [27] has also been shown to influence interlimb transfer of sensorimotor adaptation [34] and both deafferented subjects were strongly lateralized, which in our task appears to facilitate interlimb transfer [13]. Such facilitation may reflect a greater involvement of the dominant left hemisphere (in right handers) when using the right or the left hand, given that the left hemisphere is specialized for the control of limb dynamics [35], is activated when using either arm [36,37] and its damage can impair both right and left hand movements [35]. Finally, the fact that deafferented subjects performed their reaching movements with a high peak velocity was another factor presumably facilitating interlimb transfer of force-field adaptation. Whether such movement kinematics or laterality quotient influence interlimb transfer in other conditions needs to be tested.

\section{Acknowledgments}

We would like to thank Dr Matonti and D. Lenzini for examining GL and IW visual system, and Dr Paolino, Dr Devèze and L. Borel for examining GL vestibular system. We also thank F. Buloup and T. Coyle for providing technical expertise. This work benefited from the financial support of the Institute of Movement Sciences ( $\mathrm{ACI}$ and GL visit), Aix-Marseille University (International Relations grant), the Royal Society (International Exchanges grant) and the CNRS (PICS, DEFISENS and AUTON programs). Last but not least, we would like to thank GL and IW for participating in our experiments.

\section{References}

[1] P.-M. Bernier, R. Chua, C. Bard, I.M. Franks, Updating of an internal model without proprioception: a deafferentation study, NeuroReport. 17 (2006) 1421-1425, http://dx.doi.org/10.1097/01.wnr.0000233096.13032.34.

[2] M.M. Cohen, Visual feedback, distribution of practice, and intermanual transfer of prism aftereffects, Percept. Mot. Skills 37 (1973) 599-609, http:// dx.doi.org/10.2466/pms.1973.37.2.599.

[3] Z. Ghahramani, D.M. Wolpert, Modular decomposition in visuomotor learning, Nature 386 (1997) 392-395, http://dx.doi.org/10.1038/386392a0.

[4] K. Pipereit, O. Bock, J.-L. Vercher, The contribution of proprioceptive feedback to sensorimotor adaptation, Exp. Brain Res. 174 (2006) 45-52, http://dx.doi. org/10.1007/s00221-006-0417-7.

[5] R.C. Miall, J. Cole, Evidence for stronger visuo-motor than visuo-proprioceptive conflict during mirror drawing performed by a deafferented subject and control subjects, Exp. Brain Res. 176 (2007) 432-439, http://dx.doi.org/10.1007/s00221-006-0626-0.

[6] P. Dizio, J.R. Lackner, Motor adaptation to Coriolis force perturbations of reaching movements: endpoint but not trajectory adaptation transfers to the nonexposed arm, J. Neurophysiol. 74 (1995) 1787-1792.

[7] R.A. Scheidt, M.A. Conditt, E.L. Secco, F.A. Mussa-Ivaldi, Interaction of visual and proprioceptive feedback during adaptation of human reaching movements, J. Neurophysiol. 93 (2005) 3200-3213, http://dx.doi.org/10. $1152 /$ jn.00947.2004.

[8] D.W. Franklin, U. So, E. Burdet, M. Kawato, Visual feedback is not necessary for the learning of novel dynamics, PLoS One 2 (2007) e1336, http://dx.doi.org/ 10.1371 /journal.pone.0001336.

[9] C. Ghez, R. Sainburg, Proprioceptive control of interjoint coordination, Can. J. Physiol. Pharmacol. 73 (1995) 273-284

[10] J. Cole, J.L. Paillard, Living without touch and peripheral information about body position and movement: Studies with deafferented subjects, in: J.L. Bermudez, A.J. Marcel, N. Eilan (Eds.), Body Self, MIT Press, Cambridge, Mass, 1995, pp. 245-266

[11] F.R. Sarlegna, G.M. Gauthier, C. Bourdin, J.-L. Vercher, J. Blouin, Internally driven control of reaching movements: a study on a proprioceptively deafferented subject, Brain Res. Bull. 69 (2006) 404-415, http://dx.doi.org/10. 1016/j.brainresbull.2006.02.005.

[12] P. DiZio, J.R. Lackner, Congenitally blind individuals rapidly adapt to coriolis force perturbations of their reaching movements, J. Neurophysiol. 84 (2000) 2175-2180.

[13] H.Z. Lefumat, J.-L. Vercher, R.C. Miall, J. Cole, F. Buloup, L. Bringoux, et al., To transfer or not to transfer? Kinematics and laterality quotient predict interlimb transfer of motor learning, J. Neurophysiol. (2015), http://dx.doi. org/10.1152/jn.00749.2015.

[14] F.R. Sarlegna, N. Malfait, L. Bringoux, C. Bourdin, J.-L. Vercher, Force-field adaptation without proprioception: can vision be used to model limb dynamics? Neuropsychologia 48 (2010) 60-67, http://dx.doi.org/10.1016/j. neuropsychologia.2009.08.011.

[15] N. Yousif, J. Cole, J. Rothwell, J. Diedrichsen, Proprioception in motor learning: lessons from a deafferented subject, Exp. Brain Res. 233 (2015) 2449-2459, http://dx.doi.org/10.1007/s00221-015-4315-8.

[16] S.E. Criscimagna-Hemminger, O. Donchin, M.S. Gazzaniga, R. Shadmehr Learned dynamics of reaching movements generalize from dominant to nondominant arm, J. Neurophysiol. 89 (2003) 168-176, http://dx.doi.org/10 1152 /jn.00622.2002.

[17] N. Malfait, D.J. Ostry, Is interlimb transfer of force-field adaptation a cognitive response to the sudden introduction of load? J. Neurosci. 24 (2004) 8084-8089, http://dx.doi.org/10.1523/JNEUROSC.I1742-17404.2004.

[18] J. Wang, R.L. Sainburg, Interlimb transfer of novel inertial dynamics is asymmetrical, J. Neurophysiol. 92 (2004) 349-360, http://dx.doi.org/10.1152/ jn.00960.2003.

[19] J.M. Galea, R.C. Miall, D.G. Woolley, Asymmetric interlimb transfer of concurrent adaptation to opposing dynamic forces, Exp. Brain Res. 182 (2007) 267-273, http://dx.doi.org/10.1007/s00221-007-1069-y.

[20] C. Stockinger, B. Thürer, A. Focke, T. Stein, Intermanual transfer characteristics of dynamic learning: direction, coordinate frame, and consolidation of interlimb generalization, J. Neurophysiol. (2015), http://dx.doi.org/10.1152/ jn.00727.2015. 
[21] W.M. Joiner, J.B. Brayanov, M.A. Smith, The training schedule affects the stability, not the magnitude, of the interlimb transfer of learned dynamics, J. Neurophysiol. 110 (2013) 984-998, http://dx.doi.org/10.1152/jn.01072.2012.

[22] T.A. Martin, J.G. Keating, H.P. Goodkin, A.J. Bastian, W.T. Thach, Throwing while looking through prisms, Brain 119 (1996) 1199-1211, http://dx.doi.org/ 10.1093/brain/119.4.1199.

[23] M.P. Veldman, I. Zijdewind, S. Solnik, N.A. Maffiuletti, K.M.M. Berghuis, M. Javet, et al., Direct and crossed effects of somatosensory electrical stimulation on motor learning and neuronal plasticity in humans, Eur. J. Appl. Physiol. (2015), http://dx.doi.org/10.1007/s00421-015-3248-z.

[24] R. Forget, Y. Lamarre, Postural adjustments associated with different unloadings of the forearm: effects of proprioceptive and cutaneous afferent deprivation, Can. J. Physiol. Pharmacol. 73 (1995) 285-294.

[25] E. Guillaud, M. Simoneau, J. Blouin, Prediction of the body rotation-induced torques on the arm during reaching movements: evidence from a proprioceptively deafferented subject, Neuropsychologia 49 (2011) 2055-2059, http://dx.doi.org/10.1016/j.neuropsychologia.2011.03.035.

[26] B.L. Day, J. Cole, Vestibular-evoked postural responses in the absence of somatosensory information, Brain 125 (2002) 2081-2088.

[27] R.C. Oldfield, The assessment and analysis of handedness: the Edinburgh inventory, Neuropsychologia 9 (1971) 97-113, http://dx.doi.org/10.1016/ 0028-3932(71)90067-4.

[28] J.M. Goldberg, C. Fernandez, Responses of peripheral vestibular neurons to angular and linear accelerations in the squirrel monkey, Acta Otolaryngol. (Stockh.) 80 (1975) 101-110, http://dx.doi.org/10.3109/00016487509121307.

[29] F.R. Sarlegna, P.K. Mutha, The influence of visual target information on the online control of movements, Vision Res. 110 (Part B) (2015) 144-154, http:// dx.doi.org/10.1016/j.visres.2014.07.001.
[30] J.R. Crawford, D.C. Howell, Comparing an individual's test score against norms derived from small samples, Clin. Neuropsychol. 12 (1998) 482-486, http:// dx.doi.org/10.1076/clin.12.4.482.7241.

[31] A. Williams, P.L. Gribble, Observed effector-independent motor learning by observing, J. Neurophysiol. 107 (2011) 1564-1570, http://dx.doi.org/10.1152/ jn.00748.2011.

[32] A. Melendez-Calderon, L. Masia, R. Gassert, G. Sandini, E. Burdet, Force field adaptation can Be learned using vision in the absence of proprioceptive error, IEEE Trans. Neural Syst. Rehabil. Eng. 19 (2011) 298-306, http://dx.doi.org/10. 1109/TNSRE.2011.2125990.

[33] H.G. Wu, Y.R. Miyamoto, L.N.G. Castro, B.P. Ölveczky, M.A. Smith, Temporal structure of motor variability is dynamically regulated and predicts motor learning ability, Nat. Neurosci. (2014) 312-321, http://dx.doi.org/10.1038/nn. 3616.

[34] C. Chase, R. Seidler, Degree of handedness affects intermanual transfer of skill learning, Exp. Brain Res. 190 (2008) 317-328, http://dx.doi.org/10.1007/ s00221-008-1472-z.

[35] R.L. Sainburg, Convergent models of handedness and brain lateralization, Front. Psychol. 5 (2014), http://dx.doi.org/10.3389/fpsyg.2014.01092.

[36] E.-M. Pool, A.K. Rehme, G.R. Fink, S.B. Eickhoff, C. Grefkes, Handedness and effective connectivity of the motor system, NeuroImage 99 (2014) 451-460, http://dx.doi.org/10.1016/j.neuroimage.2014.05.048.

[37] S.G. Kim, J. Ashe, K. Hendrich, J.M. Ellermann, H. Merkle, K. Uğurbil, et al., Functional magnetic resonance imaging of motor cortex: hemispheric asymmetry and handedness, Science 261 (1993) 615-617. 